\title{
Considerações básicas sobre pesquisa em sala de aula
}

\author{
Jerônimo Coura Sobrinho \\ Centro Federal de Ensino Tecnológico de Minas Gerais \\ Sérgio Raimundo Elias da Silva \\ Universidade Federal de Ouro Preto
}

\section{Abstract}

This paper discusses some general elements on classroom research through a brief idea of this type of research as well as through some basic concepts about it. In addition, the most common research methods used in this context are described and the ways to collect and analyse the data are discussed. 


\section{INTRODUÇÃO}

sala de aula enquanto contexto que propicia a construção
de conhecimento é um espaço ainda pouco estudado.
Apesar de ter sido considerada uma "caixa preta" (Long, 1980:3), a sala de aula tem subsidiado pesquisas que têm revelado dados cruciais para a compreensão do processo de ensino e aprendizagem.

A pesquisa em sala de aula lida com problemas práticos que são enfrentados por professores e alunos e pode ser vista como uma atividade de aquisição de conhecimento ou de solução de problemas. Allwright e Bailey (1991:1) afirmam que este tipo de pesquisa se assemelha à pesquisa antropológica, já que os pesquisadores tentam entender o que se passa em um contexto cultural e social específico: a própria sala de aula.

No caso da sala de aula de línguas, a pesquisa tem contribuído para ampliar a compreensão da aquisição de língua estrangeira (L2) e diminuir a distância entre a teoria e a prática do processo de ensino e aprendizagem. A forma de correção dos erros dos alunos, as características do insumo lingüístico e os aspectos interacionais são exemplos de tópicos de pesquisa neste contexto. Segundo van Lier (1988:86), “...a sala de aula não ocorre em um vácuo. Antes da aula, os alunos vêm de algum lugar e depois da aula vão a outro. O que acontece nestes lugares inevitavelmente tem repercussões importantes em sala de aula." Portanto, é crescente o interesse de pesquisadores por este contexto enquanto variável importante na pesquisa em L2, principalmente entre aqueles que levam em conta fatores sociais em seus modelos teóricos.

Este trabalho propõe tecer considerações gerais sobre a pesquisa em sala de aula através de um breve histórico sobre o 
surgimento deste tipo de pesquisa e de seus conceitos básicos. A seguir, os métodos de pesquisa mais adotados neste contexto são descritos e, finalmente, a coleta e análise de dados são discutidas.

\section{BREVE HISTÓRICO}

As primeiras pesquisas em sala de aula de línguas foram desenvolvidas no começo dos anos 50, com a finalidade de avaliar o desempenho de futuros professores ao utilizarem uma determinada técnica de ensino. Já nos anos 60, as pesquisas visavam investigar a eficácia do uso dos métodos considerados antigos (Gramática e Tradução, por exemplo) e das tendências do Audiolingual. Como tais estudos não apresentaram resultados conclusivos, e levando-se ainda em conta a potencialidade do contexto de sala de aula, a interação passou a ser investigada.

$\mathrm{Na}$ última década, alguns pesquisadores começaram a se interessar em examinar como as pessoas interagem em sala de aula e como coletivamente criam oportunidades para aprender. A sala de aula passou a ser vista como um lugar onde se estuda o processo de aprendizagem através do insumo fornecido pelo professor, através das falas dos alunos e através da interação como formas de propiciar a aprendizagem.

\section{CONCEITOS BÁSICOS DA PESQUISA EM SALA DE AULA}

De uma maneira geral, os critérios pelos quais se avaliam pesquisas em sala de aula são a confiabilidade, a validade e a generalização.

A confiabilidade de uma pesquisa é baseada no princípio de que os procedimentos devem ser consistentes. Isto é, pesquisadores diferentes devem obter resultados semelhantes quando usarem os mesmos procedimentos de coleta e análise de dados.

O segundo conceito básico - a validade - está diretamente relacionado à pesquisa experimental, que pressupõe dois grupos de 
sujeitos: experimental e de controle. Diz-se, portanto, que um estudo tem validade quando seus resultados podem ser justificados em função do tratamento dado ao grupo experimental, ao serem comparados aos do grupo de controle.

O último critério de avaliação das pesquisas em sala de aula é a generalização, que está diretamente relacionada à pesquisa experimental e aos conceitos de população (todos os sujeitos que apresentam as mesmas características) e amostra (um grupo de sujeitos representativo de uma população). Já que a pesquisa experimental visa generalizar seus resultados além da amostra investigada, esta deve ser selecionada aleatoriamente a partir da população.

Van Lier (1988:2) argumenta que a generalização não pode ser um fator dos mais importantes no caso das pesquisas em sala de aula de línguas, já que a análise dos dados de uma pesquisa experimental pode deixar escapar particularidades que, por não serem recorrentes, não são consideradas relevantes.

\section{MÉTODOS DE PESQUISA EM SALA DE AULA}

Allwright e Bailey (1991:35) consideram a existência de três métodos de pesquisa em sala de aula: estudos experimentais, pesquisação e pesquisa de natureza etnográfica. As diferenças entre metodologias de pesquisa são baseadas nos conceitos de intervenção / controle. No caso da pesquisa experimental, o pesquisador exerce um alto nível de controle dos eventos através de um tratamento junto ao grupo experimental, e posteriormente avalia o efeito deste tratamento. Na pesquisação, há também intervenção direta do pesquisador, a partir da identificação de um problema e pouco controle das variáveis. Na pesquisa de natureza etnográfica, por outro lado, o pesquisador tenta não controlar os eventos.

A pesquisa experimental busca obter resultados generalizáveis. A pesquisação, por definição, procura soluções para problemas bem específicos, em contextos específicos, na tentativa de aprimorar a 
prática de sala de aula. Vale dizer que a generalização é muito importante na pesquisa experimental, mas secundária na pesquisação. Considera-se ser impossível observar e controlar todas as variáveis de uma pesquisa. Sabe-se, porém, que na pesquisa de base etnográfica tenta-se descrever todas as variáveis observáveis. Assim sendo, a pesquisa de base experimental, que pressupõe formação aleatória dos grupos (experimental e de controle) e tratamento diferenciado dos mesmos, torna-se pouco adequada à sala de aula, apesar de ser adequada a outros contextos. Para Nunan (1989:76), o que se percebe em sala de aula é fruto não só de instrumentos e métodos de observação, mas também de atitudes e crenças sobre o que acontece neste contexto. Isto mostra que é, no mínimo, difícil observar uma sala de aula de forma imparcial.

\section{COLETA E ANÁLISE DE DADOS EM PESQUISA EM SALA DE AULA}

Antes de tomar decisões sobre o tipo de instrumento a ser usado, recomenda-se decidir sobre o que observar, se a observação vai ajudar a responder o questionamento da pesquisa, quais as características e limitações do espaço físico da sala de aula, bem como qual equipamento deve ser utilizado para a coleta. Se o pesquisador quiser, por exemplo, estudar o uso de gestos do professor durante uma aula, terá de filmá-la; mas, se estiver interessado apenas na pronúncia dos aprendizes, basta gravar a aula para obter os dados necessários.

Na investigação da sala de aula, duas abordagens são possíveis. Na primeira, o pesquisador é quem decide antecipadamente o que investigar. Neste caso, a pergunta da pesquisa e os processos de coleta e análise dos dados são planejados especificamente para testar a hipótese ou responder à pergunta. Na segunda forma de investigação, as reflexões surgem a partir dos dados coletados.

A pesquisa em sala de aula pode ser desenvolvida de maneira eclética, adotando-se diferentes abordagens de pesquisa, em função do que se pretende observar. Nesta perspectiva, o pesquisador deve 
conhecer diversos instrumentos de coleta de dados, estar atento aos acontecimentos no decorrer da aula e saber registrá-los, a fim de compor sua base de dados.

Com o objetivo de compreender o que se passa em sala de aula, os dados podem ser coletados através de observação participada ou não participada (com ou sem a participação do professor), gravação, levantamento de opiniões, introspecção, testes, questionários e entrevistas. Alguns cuidados devem ser tomados na elaboração dos instrumentos de coleta, como por exemplo, observar se as perguntas estão formuladas adequadamente, de forma a não interferir nas respostas dos informantes.

A presença do observador ou dos aparatos usados para gravação pode causar mudança de comportamento dos sujeitos envolvidos no contexto da sala de aula, gerando dados que não representam a realidade deste contexto. A gravação, portanto, não se presta a investigar, por exemplo, o grau de ansiedade de um aluno.

É inevitável que a observação seja o elemento mais importante na pesquisa em sala de aula. A pesquisa com observação participada geralmente tem um caráter longitudinal, isto é, o pesquisador necessariamente observa uma série de aulas a fim de coletar os dados de seu interesse. Por outro lado, a coleta de dados de pesquisa com observação não participada pode ser feita até em uma única aula, através de gravação em áudio e/ou vídeo e posterior transcrição.

$\mathrm{Na}$ coleta de dados através de introspecção, o pesquisador grava e transcreve uma aula e, posteriormente, pede ao professor e/ou alunos que reflitam e comentem sobre ela. Este instrumento de coleta permite que tanto os professores e alunos quanto os pesquisadores apresentem suas várias interpretações sobre os eventos em sala de aula. Isto pode representar uma contribuição significativa para a compreensão dos processos de ensino e aprendizagem, o que dificilmente seria obtido através de outros instrumentos de coleta de dados.

A transcrição de falas consome muito tempo (aproximadamente 20 vezes o tempo da interação), mas fornece dados sobre a 
interação ou uso da língua que não aparecem em formulários. No caso dos formulários, qualquer observador que receba treinamento mínimo é capaz de registrar comportamentos contáveis, no momento da interação. Portanto, para a coleta de dados sobre interação em sala de aula, alguns instrumentos são mais adequados que outros, dependendo do aspecto que se pretende observar.

\section{CONSIDERAÇÕES FINAIS}

Sabe-se muito pouco sobre a sala de aula e, para aumentar este conhecimento, a pesquisa em sala de aula pode representar uma contribuição significativa, caso esse contexto seja adequadamente explorado. Para isto, faz-se necessário considerar sua diversidade, no que se refere não só aos aspectos lingüísticos e processos cognitivos, como também ao contexto social no qual a sala de aula está inserida.

A pesquisa experimental, associada às análises estatísticas, tem fracassado enquanto método de pesquisa em sala de aula, abrindo, conseqüentemente, espaço para outras metodologias. Esse fracasso está diretamente relacionado à complexidade do processo de ensino e aprendizagem de L2, considerando-se a dificuldade de isolamento das variáveis passíveis de observação no contexto de sala de aula. Apesar da metodologia experimental e a de base etnográfica serem duas vertentes diretamente opostas, a pesquisa em sala de aula tem mostrado que é possível associar características inerentes às duas metodologias, sem perder de vista seu caráter científico.

Como o principal objetivo da pesquisa em sala de aula de línguas é promover a proficiência do aprendiz, parece que resultados mais significativos podem ser alcançados se um maior número de variáveis (metodologias, crenças, motivação, atitude/aptidão, entre outras) que interferem no processo de ensino e aprendizagem em sala de aula forem avaliadas. Desta forma, o professor terá mais elementos para analisar e compreender sua própria realidade, incrementar sua prática de sala de aula e, com isso, obter resultados mais satisfatórios. 
Vale ainda resgatar a idéia de que seria pertinente desenvolver uma metodologia de pesquisa própria para a sala de aula, mesmo que esta apresente características inerentes às metodologias já descritas. Uma metodologia mais adequada pode gerar resultados mais eficazes para a compreensão dos processos de ensino e aprendizagem que se desenvolvem na sala de aula.

\section{BIBLIOGRAFIA}

ALLWRIGHT, D. \& BAILEY, K. M. Focus on the language classroom. Cambridge: Cambridge University Press, 1991.

LONG, M. H. Inside the "black box": methodological issues in research on language teaching and learning. Language learning 30: 1-42. 1980.

LOPES, L. P. M. Oficina de lingüística aplicada. Campinas: Mercado das Letras, 1996.

NUNAN, D. Research methods in language learning. Cambridge: Cambridge University Press, 1992. . Understanding language classrooms. New York: Prentice Hall, 1989.

VAN LIER, L. The classroom and the language learner. London: Longman, 1988. 